FACTA UNIVERSITATIS

Series: Mechanical Engineering Vol. 17, No 2, 2019, pp. 103 - 112

https://doi.org/10.22190/FUME190326017O

Original scientific paper

\title{
HIGH-FREQUENCY VIBRATIONS IN THE CONTACT OF BRAKE SYSTEMS
}

\author{
Johannes Otto, Georg-Peter Ostermeyer
}

Technische Universität Braunschweig, Braunschweig, Germany

\begin{abstract}
The processes and interactions that occur due to friction in the brake are still not fully understood today. In particular, the processes in the boundary layer have been shown to be responsible for a variation in the coefficient of friction and the associated wear. Dynamic contact structures in the boundary layer are made responsible for this behaviour. Vibration analyses on brake systems usually concentrate on operating vibrations analyses of the brake system components. In order to gain an understanding of the cause of such phenomena and oscillations, it is necessary to understand the mechanism of origin in the contact area. Therefore, highly specialized tribotesters have been developed at the Institute for Dynamics and Vibration to investigate the dynamic processes through experiments and simulative investigations. It can be shown that ultrasonic frequencies are generated in the friction boundary layer. These ultrasonic frequencies could not only be found in pin-on-disc testers, but also in complete vehicle brake systems. It was possible to identify that the vibration signatures between 20 and $80 \mathrm{kHz}$ depend on a whole series of different influencing variables and have no dependence on the testing machine. In connection with the friction theories, it is an open question whether these oscillations can be made responsible as a kind of trigger pulse for the squealing of 1 to $20 \mathrm{kHz}$. In addition, it is a problem that the parking sensors installed in the vehicle work on an ultrasonic basis in the same frequency range and can therefore lead to failure due to these frequencies.
\end{abstract}

Key Words: High Frequency, Vibrations, Ultrasonic, Boundary Layer, Noise

\section{INTRODUCTION}

The phenomena of friction are still not fully understood and difficult to predict. The friction itself is an essential component between two bodies when they are in contact and moved against each other. As a rule, the dissipation of energy from the system is undesirable as it reduces the efficiency of the system. Nevertheless, there are systems, such as the

Received March 26, 2019 / Accepted May 22, 2019

Corresponding author: Johannes Otto

TU Braunschweig, Inst. f. Dynamik und Schwingungen, Schleinitzstraße 20, 38106 Braunschweig, Germany

E-mail: j.otto@tu-bs.de 
friction brake, in which high friction is desired. The general goals are that the friction brake can transmit maximum friction power, has low wear rate and high resistance to Noise Vibrations and Harshness (NVH). A large number of research projects have shown that the objectives mentioned above are significantly influenced by the friction boundary layer in the case of high-load contacts, see for example [1]. The friction boundary layer is often referred to as the third body and describes the contact area between the brake pad and brake disc. However, the friction boundary layer is dependent on a number of different parameters, which makes the predictability of friction in contact particularly difficult. In order to make a scientific contribution to this complex topic, this work focuses on the topic of frictioninduced high-frequency oscillations within the boundary layer between brake pad and brake disc. Fundamental investigations will be carried out in order to gain a systematic understanding of the high-frequency friction-induced vibrations within the contact. This paper deals with the high-frequency oscillations in the range of 20 to $80 \mathrm{kHz}$.

\section{THE PROCESS IN THE BOUNDARY LAYER}

The tribological properties are determined by the processes and interactions that occur between the brake pad and the brake disc. Within the boundary layer, highly complex dynamic processes occur which are significantly influenced by hard, load carrying contact patches $[2,3]$.

The development process of a patch begins with a wear-resistant particle that comes into frictional contact with the brake disc as a result of the progressive wear of the surrounding material. These abrasive particles can often be identified by EDX analysis as steel fibers [4], but also as quartz particles [5]. At this point between the particle and the disc, the movement of the wear material is prevented and the wear material accumulates. As a result, the hard particles begin to carry an increased proportion of the frictional and normal force and thus cause a strong and local increase in temperature. The combination of high local temperatures and normal pressure leads to sintering processes within the boundary layer. As a result, contact patches are formed as shown in Fig. 1.

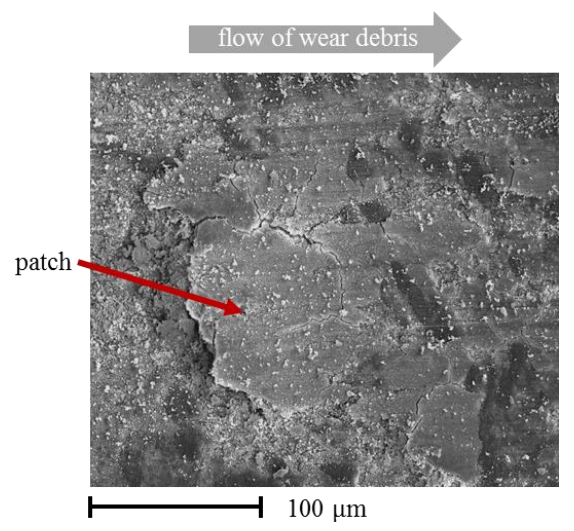

Fig. 1 Patch structure on the brake pad surface [6] 
In the further friction process, the high mechanical and the thermal stresses lead to the formation of cracks within the contact plateaus and to destruction.

Simulation investigations by Ostermeyer using multi-body systems indicate the excitation of high-frequency oscillations within the boundary layer resulting from self-organization of the patches [7]. In addition, it can be seen in [8] that wave propagation can occur in friction contact and excite frequencies in the ultrasonic range. The question now arises whether the postulated high-frequency oscillations can be recorded by metrological investigations. Therefore, this paper presents an experimental study of friction-induced high-frequency oscillations within the boundary layer. In the past, a number of authors investigated the influence of external ultrasound on the friction contact $[9,10,11]$. It was found that the excitation amplitude of the high-frequency oscillations applied from the outside have a significant influence on the coefficient of friction.

\section{MEASURING DEVICE AND INVESTIGATION OF THE DyNAMICS OF THE TEST UNIT}

The test device mainly used for the following investigations is a scaled Automated Universal Tribotester (AUT), Fig. 2. The AUT is a high-precision and fully automated pindisc tribometer. The brake disc is set in rotation by an electric motor and speed characteristics, as they occur in conventional motor vehicles, can be realized by an intelligent motor control. The other friction partner is the brake pad. A brake pad sample of $20 \times 10 \mathrm{~mm}^{2}$ is sawn from the brake pad and glued into a sample holder, see the brake pad sample in Fig. 3. In [12] the comparability between scaled pin-on-disc testers and dynamometer test benches was investigated. It was found that the dynamic variation of the coefficient of friction is the same and that only the absolute magnitude of the coefficient of friction differs slightly. By mounting the specimen holder on the load unit, forces or pressures can be realized as they occur in any vehicle. For further information on the test equipment, see the publication [13].

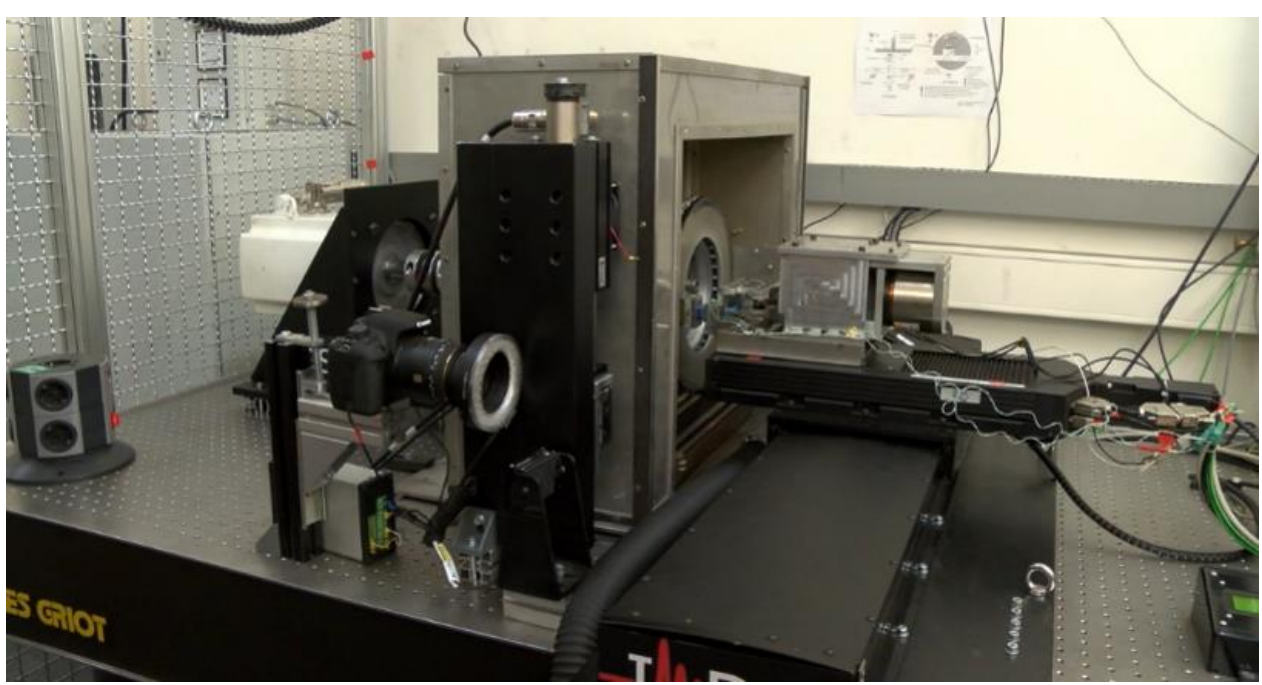

Fig. 2 Automated Universal Tribotester 
Two different measuring instruments are available at the IDS to measure the highfrequency vibrations between the brake pad and the brake disc. The first is the Laser Doppler Vibrometer with the decoder which has a sampling rate of up to $2.5 \mathrm{MHz}$ and the second is an Ultrasonic Microphone with a sampling rate of up to $0.5 \mathrm{MHz}$. In order to measure the vibrations synchronously during the brake application, a fully automated measurement chain was realized, see paper [14].

The dynamic behaviour of the experimental system was investigated using complex eigenvalue analysis [14]. It was found that the first eigenfrequencies of the system components are below $1 \mathrm{kHz}$ and that in the frequency range to be investigated a large number of eigenfrequencies are close to each other.

\section{Proof of High-FreQuency Vibrations in Friction CONTACT}

\subsection{Comparison between Laser Vibrometer and Ultrasonic Microphone}

The resulting high-frequency vibrations in friction contact between the brake pad sample and the brake disc at the AUT are measured by using the Laser Doppler Vibrometer and the Ultrasonic Microphone. The laser is focused alternately on the tangential and radial friction surfaces of the friction sample. To ensure optimum signal quality, reflective foils are bonded to the friction pad surfaces. The Ultrasonic Microphone is adjusted at an angle of $45^{\circ}$ between tangential and radial coordinates. The measurement setup is shown in Fig. 3. The brake applications are performed under constant boundary conditions, which means constant speed, constant pressure, constant starting temperature. Before the measurement, a complete bedding procedure is carried out with the aim of ensuring a full-surface contact and stationary behaviour of the friction boundary layer.

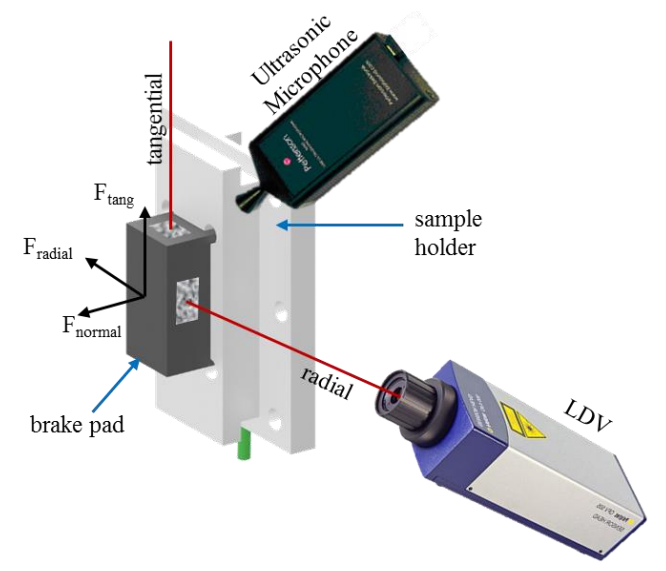

Fig. 3 Measurement Setup [14]

The measured frequency spectra can be seen in Fig. 4. The left side shows the frequency spectrum from the Laser Vibrometer in the tangential friction direction. On the ordinate the amplitude of the velocity is shown in $\mathrm{m} / \mathrm{s}$ and on the abscissa the frequency between 10 and $200 \mathrm{kHz}$. Looking at the spectrum, peaks can be identified at $16 \mathrm{kHz}, 19 \mathrm{kHz}$, 
$37 \mathrm{kHz}$ and $56 \mathrm{kHz}$. A comparison with the frequency spectrum recorded simultaneously by the Ultrasonic Microphone shows these same frequencies. In addition, a frequency at $24 \mathrm{kHz}$ can also be detected in the microphone's spectrum. This frequency can be determined in the radial spatial direction of the friction sample. In conclusion, it can be seen that highfrequency oscillations between brake pad and brake disc can be detected by two different measuring principles. In addition, it can be determined that all frequencies measured in the individual spatial directions of the laser can also be detected by the $45^{\circ}$ mounting of the Ultrasonic Microphone.
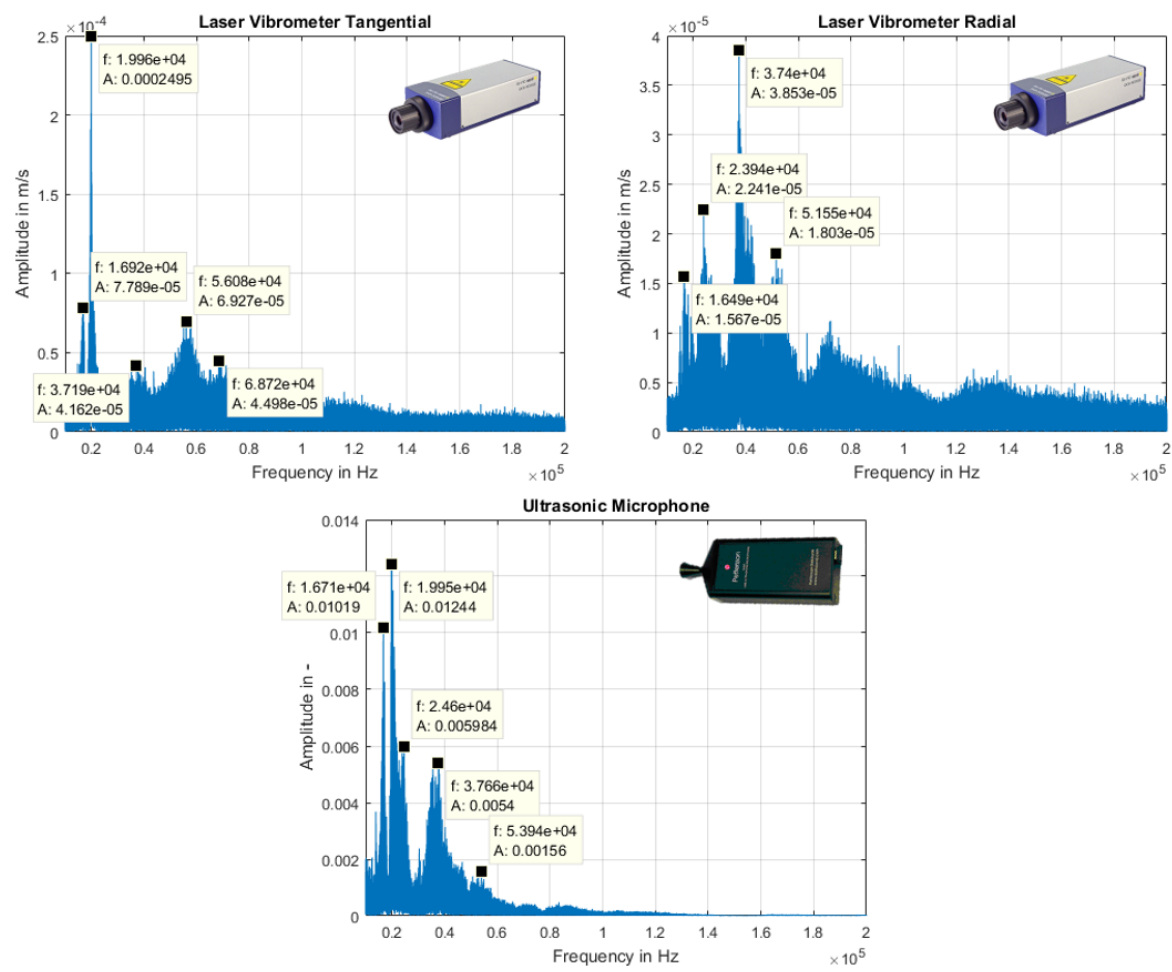

Fig. 4 Measurement results of the Laser Vibrometer and the Ultrasonic Microphone [14]

\subsection{Investigation of the Influence of the Friction Direction and the Sample Holder}

In this section the influence of the specimen geometry and the specimen holder itself on the high-frequency vibrations shall be examined. For this purpose, two brake pad samples with dimensions $20 \times 10 \mathrm{~mm}^{2}$ and $10 \times 20 \mathrm{~mm}^{2}$ were produced. In addition, a special specimen holder was developed and manufactured which allows the brake pad specimen to be glued in place rotated by $90^{\circ}$, see illustration at top right. The tests are carried out under constant boundary conditions. Before the actual measurement, a bedding procedure is carried out to achieve a full-surface contact and a constant boundary layer. The Laser Vibrometer is focused on the surface of both samples in tangential friction direction, see Figure 5 in the top for clarification. 

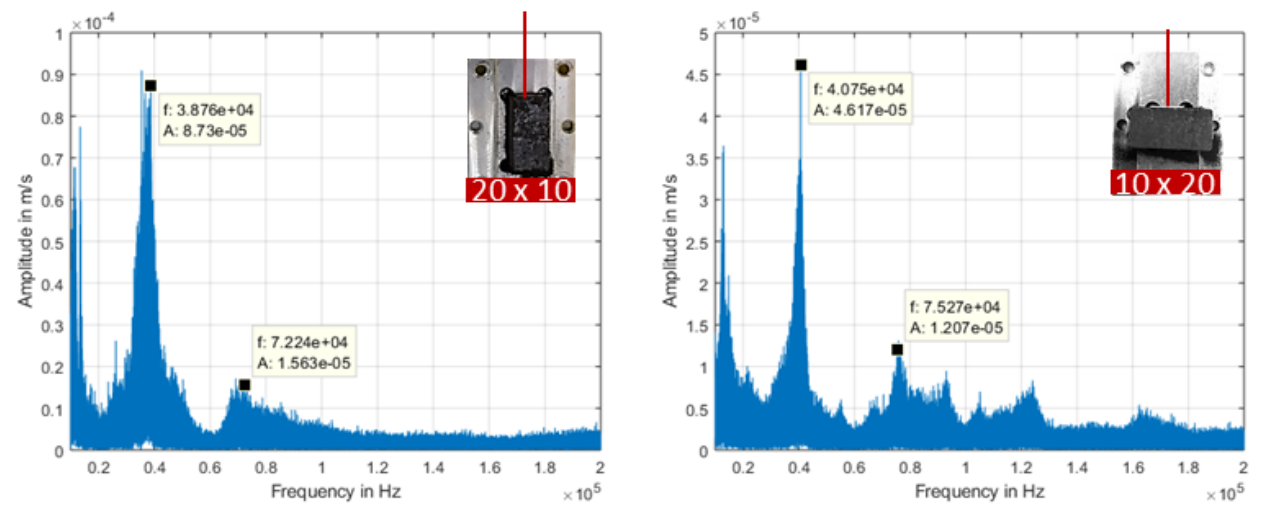

Fig. 5 Investigation of the same brake pad sample in two different friction directions, initial state left and turned sample right

If the experiments are now carried out, the frequency spectrum for the initial state results is shown in the figure on the left side. In particular, the high peak at approximately $39 \mathrm{kHz}$ can be identified. On the right side of the figure, the frequency spectrum of the rotated sample can be seen. A significant increase in amplitude at $40 \mathrm{kHz}$ can also be seen here. In addition, an amplitude increase in the range of $74 \mathrm{kHz}$ can be observed for both frequency spectra.

Thus, this investigation indicates that the specimen holder and the specimen geometry have no influence on the induced vibrations. Furthermore, it can be determined that a different friction material shows a different frequency spectrum under the same conditions: compare Fig. 5 and Fig. 4.

\subsection{Investigation of the Influence of the Sample Length}

The longer the period of time that a brake pad is installed in a vehicle, the lower is the brake pad height. Therefore, possible influence of the brake pad length (pad height) or the sample length on the high-frequency vibrations is to be investigated here. Two characteristic tests are carried out for this purpose. The first test is carried out with the initial brake pad sample. This has a length of $15.2 \mathrm{~mm}$. The measuring direction of the laser is in the tangential friction direction. The resulting frequency spectrum under constant boundary conditions is shown in Fig. 6 on the left. Significant frequencies at $14.7 \mathrm{kHz}, 19.3 \mathrm{kHz}$ and $45 \mathrm{kHz}$ can be identified. This sample is then reduced to $11 \mathrm{~mm}$ using the milling manufacturing process and afterwards a running-in procedure is performed. This ensures a constant initial condition. The test is repeated. It can be seen that the frequency at $44 \mathrm{kHz}$ is independent of the sample length. The frequency at $14.7 \mathrm{kHz}$ in the left output state increases to $15.8 \mathrm{kHz}$. This can be justified by the fact that the eigenvalue analysis and operating vibration shape analyses of the brake pad sample identified a natural frequency in the tangential direction of the brake pad sample in the order of $15 \mathrm{kHz}$ [14].

In summary, it can be stated at this point that the high-frequency oscillations are independent of the brake pad sample length. 

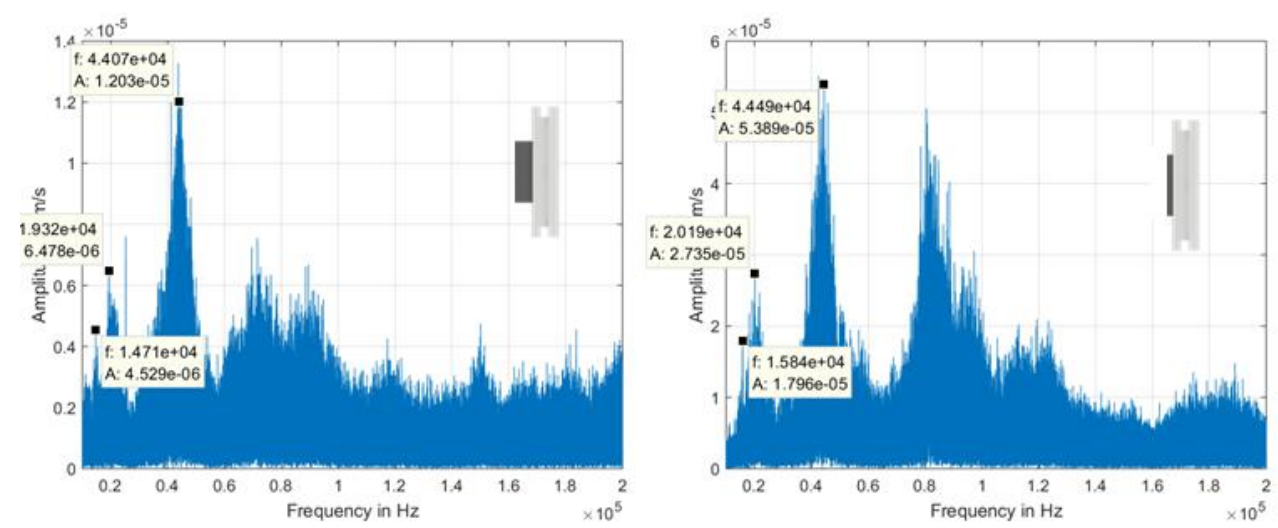

Fig 6 Investigation of the Influence of the Sample Length, Initial State left and Worn State right

\subsection{Investigation of the same Friction Pairing at different Test Devices}

At this point, the extent to which the test equipment has an influence on the highfrequency oscillations shall be investigated. The same friction pairing (disc and brake pad) are investigated on two different pin-disc tribometers. In the first step, the measurements are carried out at the AUT, where the previous investigations were also carried out. In the second step, the brake disc and the brake pad are mounted on the VVT (Variable Velocity Tribotester) and the measurements are carried out there. The VVT and the AUT do not differ in their test principle, but rather in their design parameters, such as stiffness, damping, inertia, etc. The investigations are carried out at a constant sliding speed and six different normal forces. Each normal force consists out of 5 measurements, each with a friction time of 5 seconds. The laser vibrometer measures the vibrations occurring on the brake pad surface in a tangential spatial direction.

Figure 7 shows the waterfall diagram for the different normal forces at the AUT on the left side and on the right side for the VVT. A high correspondence between the two frequency spectra can be seen. The frequency at about $30 \mathrm{kHz}$ increases to about $35 \mathrm{kHz}$ as the normal force increases. The amplitudes in the frequency range between 50 and 70 $\mathrm{kHz}$ is combined with increasing normal force to a frequency at $60 \mathrm{kHz}$.

This investigation thus shows that the ultrasonic oscillations in friction contact are independent of the test equipment and are much more influenced by the magnitude of the normal force.

\subsection{Investigation at a complete Brake System}

Studies also show that the same high-frequency oscillations can be found in complete brake systems (dynamometer test bench). The vibrations were recorded from the brake pad surface by means of laser vibrometers and significant frequencies in the range from 20 to $80 \mathrm{kHz}$ could also be identified here [13]. 

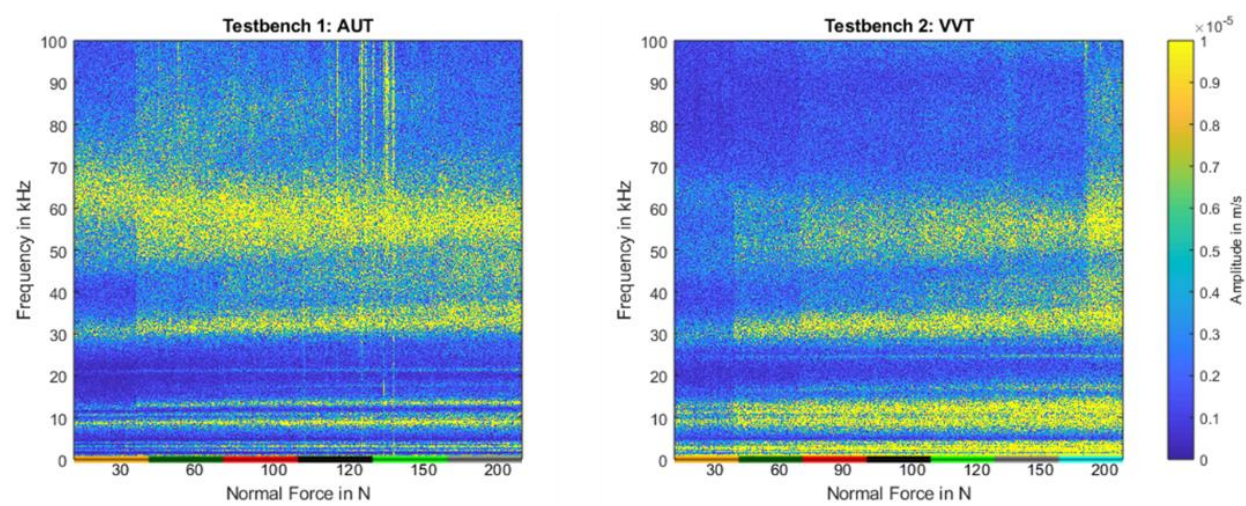

Fig. 7 Comparison between two different Testbenches [14]

\section{PASSIVE VIBRATION REDUCTION}

In the previous sections it was shown that high-frequency vibrations occur between the brake pad and the brake disc. Various factors influencing the high-frequency vibrations could be identified. In order to gain a better understanding of the system, this section will attempt to reduce the vibrations. In the literature there many different passive methods to design systems with low vibration, for example vibration damping, vibration isolation and vibration tuned mass damper are mentioned. With the first two methods mentioned, however, the problem is that they must be used directly at the source of origin and thus in the friction boundary layer itself. Therefore, this paper is focused on the use of a tuned mass damper for the high-frequency oscillation.

The tuned mass damper, a so-called "sacrificial mass" is placed on the vibrating system, which should be designed in such a way that the initial system performs as small movements as possible and the majority of the energy introduced is "transferred" into the sacrificial mass. For clarification, it can be imagined that the absorber principle is based on the properties of a specially designed dual mass oscillator. The natural frequency of the tuned mass damper $\omega_{\mathrm{T}}$ should be designed in such a way that it corresponds to the natural frequency of the system mass.

However, tuned mass dampers have the disadvantage that they only work in a certain frequency band and that new resonances are created below and above the original resonance. In order to make optimum use of the tuned mass damper, it is placed as close as possible to the friction contact. In order to be independent of the friction pairing to be investigated, a new sample holder is developed. Bending beams of different lengths can be attached to the upper side of the new sample holder (see Fig. 8). The bending beams should function as absorbers themselves. The frequency of the tuned mass damper can be varied by different lengths of the bending beams. As a basic rule, the longer the bending beam, the lower the natural frequency. The natural frequency of the bending beams was calculated in advance using the finite element method. 


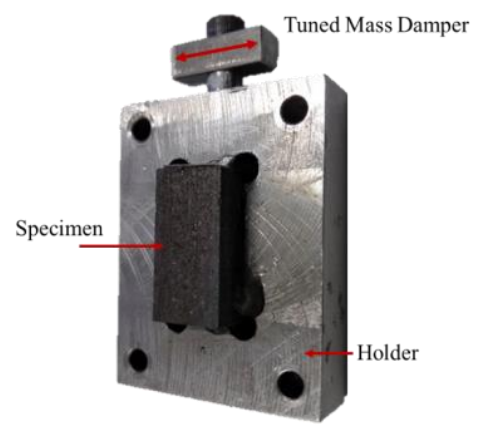

Fig. 8 Sample Holder with Tuned Mass Damper

For the subsequent tests, a friction pairing is selected which has a characteristic frequency in the range of $45 \mathrm{kHz}$. For the experiments, the Laser Doppler Vibrometer is focused on the sample surface in the tangential friction direction and is braked with constant normal force and speed. On the left side of Fig. 9, the recorded frequency spectrum of the initial state (without tuned mass damper) can be seen. Then the tuned mass damper is mounted on the sample holder and the braking is repeated under the same boundary conditions. A comparison of the two frequency spectra shows that the significant amplitude increase at $45 \mathrm{kHz}$ is no longer visible in the right image. However, new frequencies have formed just below and above. This behavior suggests that the tuned mass damper is working as expected and thus that a reduction of the high-frequency oscillations that occur in the friction boundary layer is possible. Further analyses will be carried out in the near future.
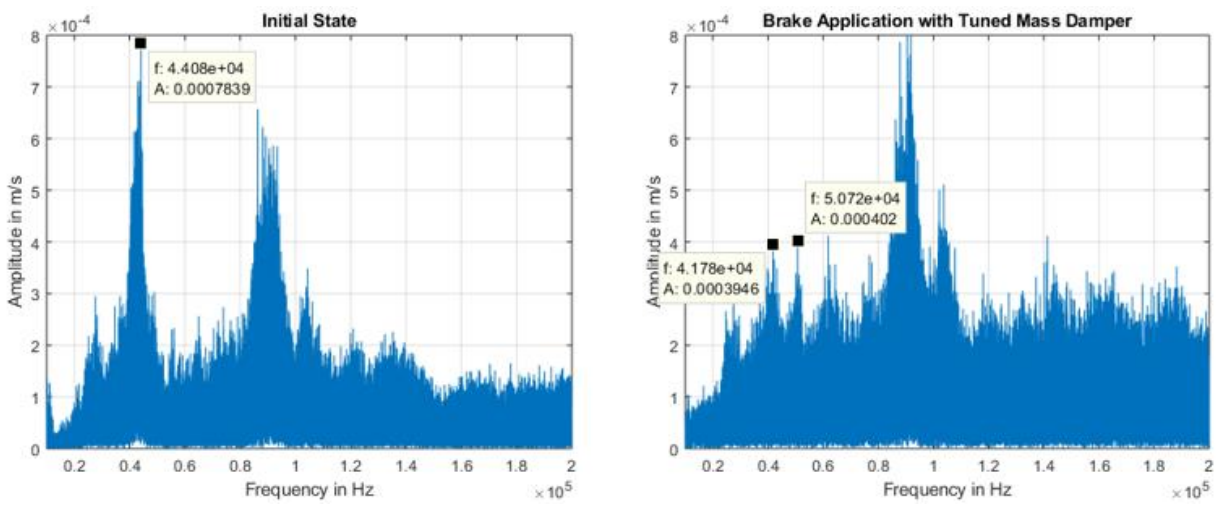

Fig. 9 Comparison between Initial State and tuned Mass Damper

\section{CONCLUSION}

The underlying physics of friction has not yet been fully understood. The large dependency on a large number of different parameters makes predictability difficult. Therefore, this work deals with the friction-induced oscillations that occur in the boundary layer between brake disc and brake pad in order to contribute to the scientific understanding of friction. 
It is possible to identify characteristic high-frequency oscillations in each brake pad disc combination, which are in the range between 20 and $100 \mathrm{kHz}$. The following points could be summarized:

- The high-frequency oscillations can be recorded with two different measuring principles.

- The high-frequency oscillations are independent of the test setup and test equipment.

- The high-frequency oscillations are dependent of the friction pairing, normal force, coefficient of friction, speed, boundary layer [14].

- The high-frequency vibrations can be recorded on the complete brake $\&$ on the pindisc tribometer.

- The high-frequency vibrations can be reduced with a Tuned Mass Damper. This allows new studies to be carried out to investigate the friction behavior during a reduction in vibrations.

In summary, high-frequency oscillations are excited in the boundary layer. The extent to which these are relevant for the NVH phenomena described and what the decisive excitation mechanism is will be discussed in further investigations.

\section{REFERENCES}

1. Ostermeyer, G., Wilkening, L., 2013, Experimental investigations of the topography dynamics in brake pads, SAE Int. J. Passeng. Cars - Mech. Syst., 6(3), pp. 1398-1407.

2. Eriksson, M., Jacobson. S., 2000, Tribological surfaces of organic brake pads, Tribology International, 33(12), pp. 817-827.

3. Ostermeyer, G.-P., 2009, On tangential friction induced vibrations in brake systems, SAE Int. J. Passeng. Cars-Mech. - Mech. Syst., 1(1), pp. 1251-1257.

4. Eriksson, M., Lord, J., Jacobson, S., 2001, Wear and contact conditions of brake pads: dynamical in situ studies of pad on glass, Wear, 249(3-4), pp. 272-278.

5. Österle, W., Gripentrog, M., Gross, T., Urban, I., 2001, Chemical and microstructural changes induced by friction and wear of brakes, Wear, 251(1-12), pp. 1469-1476.

6. Ostermeyer, G.-P., 2001, Friction and wear of brake systems, Forschung im Ingenieurwesen, 66, pp. 267272.

7. Ostermeyer, G.-P., 2010, Dynamic friction laws and their impact on friction induced vibrations, SAE Int. J. Passeng. Cars-Mech., pp. 1-15, doi:10.4271/2010-01-1717

8. Recke, B., Ostermeyer, G., 2018, Boundary layer dynamics and sound generation, SAE Technical Paper 2018-01-1900, pp. 1-5, doi:10.4271/2018-01-1900.

9. Pohlman, R., Lehfeldt, E., 1966, Influence of ultrasonic vibration on metallic friction, Ultrasonics, 4, pp. 178-185.

10. Littmann, W., Storck, H., Wallaschek, J., 2001, Sliding friction in the presence of ultrasonic oscillations: superposition of longitudinal oscillations, Archive of Applied Mechanics, 71(8), pp. 549-554.

11. Popov, V., Starcevic, J., Filippov, A., 2009, Influence of ultrasonic in-plane oscillations on static and sliding friction and intrinsic length scale of dry friction processes, Trib. Lett., 39(1), pp. 25-30.

12. Perzborn, N., Agudelo, C., Ostermeyer, G., 2015, On similarities and differences of measurements on inertia dynamometer and scale testing tribometer for friction coefficient evaluation, SAE International Journal of Materials and Manufacturing, 8(1), pp. 104-117.

13. Ostermeyer, G.-P., Schramm, T., Raczek, S., Bubser, F., Perzborn, N., 2015, The automated universal tribotester, presented at EuroBrake 2015, pp. 1-10.

14. Otto, J., Sandgaard, M., Ostermeyer, G.-P., 2019, High-frequency vibrations in the friction boundary layer of brake systems, EuroBrake 2019, May 2019, Dresden, Germany, pp. 1-14. 